Research Article

\title{
Extrudability and Consolidation of Blends between CGM and DDGS
}

\author{
C. J. R. Verbeek ${ }^{1}$ and Kurt A. Rosentrater ${ }^{2}$ \\ ${ }^{1}$ School of Engineering, University of Waikato, Hamilton, New Zealand \\ ${ }^{2}$ Department of Agricultural and Biosystems Engineering, Iowa State University, Ames, IA, USA
}

Correspondence should be addressed to C. J. R. Verbeek; jverbeek@waikato.ac.nz

Received 30 March 2016; Accepted 16 November 2016

Academic Editor: Philip Eisenlohr

Copyright (C) 2016 C. J. R. Verbeek and K. A. Rosentrater. This is an open access article distributed under the Creative Commons Attribution License, which permits unrestricted use, distribution, and reproduction in any medium, provided the original work is properly cited.

\begin{abstract}
During the last decade, the global biofuels industry has experienced exponential growth. By-products such as high protein corn gluten meal (CGM) and high fibre distillers dried grains with solubles (DDGS) have grown in parallel. CGM has been shown to be suitable as a biopolymer; the high fibre content of DDGS reduces its effectiveness, although it is considerably cheaper. In this study, the processing behaviour of CGM and DDGS blends was evaluated and resulting extrudate properties were determined. Prior to processing, urea was used as a denaturant. DDGS : CGM ratios of $0,33,50,66$, and $100 \%$ were processed in a single screw extruder, which solely used dissipative heating. Blends containing DDGS were less uniformly consolidated and resulted in more dissipative heating. Blends showed multiple glass transitions, which is characteristic of mechanically compatible blends. Transmission electron microscopy revealed phase separation on a microscale, although distinct CGM or DDGS phases could not be identified. On a macroscale, optical microscopy suggested that CGM-rich blends were better consolidated, supported by visual observations of a more continuous extrudate formed during extrusion. Future work should aim to also characterize the mechanical properties of these blends to assess their suitability as either bioplastic feedstock or pelletized livestock feed.
\end{abstract}

\section{Introduction}

Traditionally, the motivations behind sustained research in reducing dependence on polymers from petrochemical sources were similar to those in energy research, a decreasing fossil fuel supply with a corresponding price increase and a widespread awareness of sustainability [1]. However, today the focus may be more on the environmental side in light of current low oil prices.

Polysaccharides and proteins could partially replace petrochemical polymers and are often biodegradable [2], although this does not necessarily mean that they are renewable. Agropolymers are extracted from either plants or animals and their use has long been recognised and may be an innovative and sustainable approach to reduce reliance on petrochemical polymers [2]. Some of these polymers can be processed directly into thermoplastic materials; however, most require chemical modification to account for deficiencies such as brittleness, water sensitivity, and low strength. Common characteristics of agropolymers are their hydrophilicity, fast degradation rate, and sometimes unsatisfactory mechanical properties, particularly in wet environments [3].

The benefit of agropolymers could be even greater if they are by-products of other industries or processes. One of the most frequently used materials for bioenergy production is corn starch [4]. Two main techniques are used to produce ethanol: wet milling and dry-grind processing. For wet processing, the primary end products are corn starch, corn oil, and ethanol, obtained from separating the starch from the rest of the kernel after milling [5]. Additional end products include corn gluten feed (CGF), corn gluten meal (CGM), corn germ meal, and condensed fermented corn extractives (obtained after fermentation) [6]. Dry grinding, on the other hand, has become the primary method for ethanol production in the US, and uses the entire corn kernel [7]. After fermentation, the nonfermentable materials are usually combined, dried, and sold as "distillers dried grains with 
solubles" or DDGS. Because of its high protein content, CGM can be used to produce thermoplastic materials [8]. DDGS, on the other hand, is less expensive but is less likely to form a thermoplastic.

A major challenge for the development of thermoplastics from proteins is to rearrange protein structure during processing; this occurs in three steps [9, 10]: disrupting protein-protein interactions, plasticization, and fixation. Protein secondary structures include $\alpha$-helices, $\beta$-sheets, turns, and random coils [11] and chemical interactions such as disulphide bonds, hydrogen bonds, van der Waals forces, and hydrophobic and electrostatic interactions maintain the folded structures [12]. During extrusion, a considerable amount of mechanical energy is added to the material, which may affect final product properties. The vast amount of possible chemical interactions, combined with their heat sensitivity, leaves a small window of feasible conditions for processing [13].

During extrusion, material is conveyed through the extruder's heated barrel, inducing shear forces and increasing pressure along the barrel. Feed composition, screw speed, barrel temperature profile, and feed rate as well as die size and shape are important process variables. All of these will affect screw fill, specific mechanical energy (SME), torque, pressure at the die, residence time, and product temperature. Extrusion requires transforming the protein into a melt-like state, implying processing above the protein's softening point (or glass transition temperature), which is often very high for dehydrated proteins. To avoid degradation, additives are required for thermoplastic extrusion. Furthermore, high processing temperatures and specific mechanical energy input can cause excessive degradation and cross-linking $[13,14]$.

Di Gioia et al. studied the effectiveness of various additives on CGM processing using batch mixing and compression moulding but found that processing CGM with either water or glycerol resulted in materials that were not very cohesive [15-17]. Aqueous urea is a well-known protein denaturant, unfolds protein structures, and is an effective additive to promote protein consolidation [8]. It disrupts protein secondary structure, which could ultimately affect how chains interact with each other as well as with water [1822].

The chemical composition of DDGS and CGM is vastly different, with CGM being much richer in protein $(\sim 67$ versus $34 \%$, resp.). The higher carbohydrate content of DDGS (mainly cellulose) may impede the formation of a thermoplastic material; however, it is favourable to include some DDGS to reduce cost [23]. The objective of this research was to assess the effect of partially replacing CGM with DDGS by monitoring processability, consolidation, thermal properties, and morphology of the blends.

\section{Materials and Methods}

2.1. Materials. Corn gluten meal was obtained from Consumers Supply Distributing (Sioux City, IA, USA), while DDGS was procured from VeraSun Energies (Aurora, SD, USA), after having the lipids removed by solvent extraction
TABLE 1: Composition of the raw protein sources used in the study*

\begin{tabular}{lcc}
\hline & CGM & DDGS \\
\hline Dry matter $(\%)$ & 90.8 & 98.0 \\
Crude protein $(\% \mathrm{db})$ & 67.4 & 34.0 \\
Crude lipid $(\% \mathrm{db})$ & 2.2 & 2.7 \\
Carbohydrate $(\% \mathrm{db})$ & 28.1 & 58.5 \\
$\quad$ Neutral detergent fiber $(\% \mathrm{db})$ & 5.7 & 50.1 \\
Starch $(\% \mathrm{db})^{*}$ & 15 & 5 \\
Ash $(\% \mathrm{db})$ & 2.3 & 4.8 \\
\hline
\end{tabular}

${ }^{*}$ Analysis performed at Servitech Laboratories, Hastings, NE, USA.

[24]. Composition of each of these protein meals is provided in Table 1.

2.2. Protein Modification. Prior to processing, CGM and DDGS were mixed with $10 \mathrm{~g}$ urea (dissolved in $50 \mathrm{~g}$ water) per $100 \mathrm{~g}$ of protein meal. Materials were thoroughly mixed for $30 \mathrm{~min}$ in a rotating mixer and then sealed in plastic containers and left over night to equilibrate.

2.3. Experimental Design. Both the DDGS and the CGM protein meals were modified by combining 100 parts protein meal, 50 parts water, and 10 parts urea $24 \mathrm{~h}$ prior to processing. Blends were formulated (on a mass basis) to consist of DDGS:CGM ratios of $0: 1,1: 2,1: 1,2: 1$, and $1: 0$. Two replicate extrusion runs per each of the five blends were used, for a total of 10 extrusion runs.

2.4. Extrusion Processing. After modification, the protein sources were blended at the specified ratios and were extruded in a single screw extruder (Rietz, Extructor, Bepex International LLC, Minneapolis, MN, USA) using frictional heating alone. The screw configuration is shown in Figure 1(a) and the extruder has an L/D of 3.76. The die plate (Figure 1(b)) consisted of $62 \mathrm{~mm}$ diameter orifices, equally spaced, with a total open area of $18.9 \mathrm{~mm}^{2}$. The extruder's barrel has three sections of which the front section was fitted with two thermocouples; at the entry $\left(T_{2}\right)$ and the die $\left(T_{1}\right)$. Power consumption was continuously monitored using a power meter from HIOKI (Model 3196, HIOKI E.E. Corporation, Nagano, Japan) [25].

Extrusions were carried out in duplicate for each blend combination (i.e., $n=2$ for each treatment) following a completely randomized order. The input feed rate was set to ensure steady state operation of the extruder. After processing, the extrudates were cooled to room temperature, dried at $40^{\circ} \mathrm{C}$ for $24 \mathrm{~h}$, and then stored in sealed polyethylene bags at room temperature until further analysis.

2.5. Analysis. Particle size of the raw and modified blends was determined using a particle size analyser (Camsizer, Horiba Instruments, Irvine, CA, USA).

Heat flows and glass transition temperatures were determined using a differential scanning calorimeter (DSC 822e, 


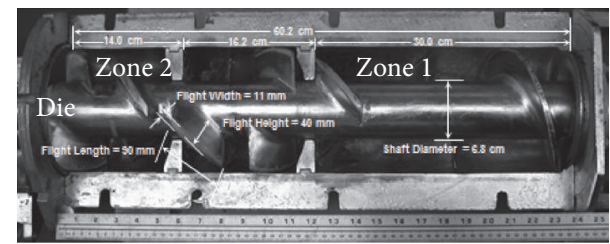

(a)

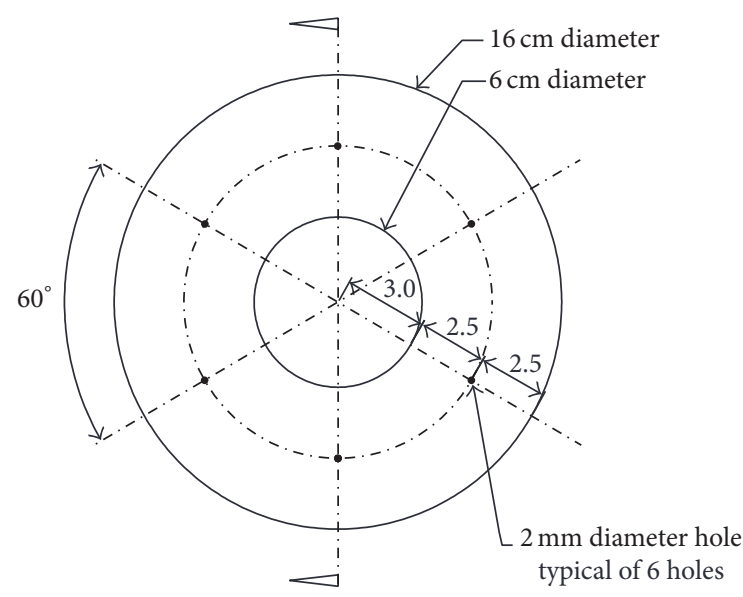

(b)

FIgURE 1: (a) Extruder barrel configuration; (b) die plate schematic.

Mettler-Toledo, Inc., Columbus, OH, USA) using hermetically sealed pans and scanning between 20 and $140^{\circ} \mathrm{C}$ at a scan rate of $50^{\circ} \mathrm{C}$, under nitrogen gas.

Consolidation was assessed based on optical images at $10 \mathrm{x}$ magnification. Optical images were collected using a digital microscope (Digital Blue, QX5), fitted with a digital camera. Each image was adjusted for brightness and contrast using ImageJ software. ImageJ was used for edge detection using colour images after which they were converted to binary images. Based on a circular section of the image the percentage black and white areas can be calculated corresponding to consolidated and nonconsolidated areas.

Transmission electron microscope images were taken using a JEOL JEM2100F field emission instrument. Samples were imbedded in epoxy after osmium tetroxide and glutaraldehyde fixation.

Moisture contents of all materials were determined by drying in a laboratory oven at $60^{\circ} \mathrm{C}$ for $24 \mathrm{~h}$.

\section{Results and Discussion}

3.1. Raw Materials. DDGS had a larger average particle size $(0.71 \mathrm{~mm})$ compared to CGM $(0.51 \mathrm{~mm})$ and blending them, in any proportion, let CGM take up the void space between DDGS particles. At larger magnification the more irregular shaped particles were evident in DDGS (Figure 2).

DDGS was low in starch, but very high in fibre (water soluble cellulose) whereas CGM had very little fibre; both had similar lipid content. CGM had about double the protein content and one would expect it to be processed into a thermoplastic easier, while DDGS' high cellulose content would likely require more energy for processing.

Both materials were effectively already a blend (morphology shown later) and blending them further changed the overall of proportion of protein, starch and cellulose. For example, in a 1:2 ratio CGM : DDGS blend, the protein content drops to about $45 \%$, with nearly the same amount of carbohydrates.
The protein meals considered here are composed not only of corn protein, but also of lipids, fibres, and other carbohydrates which all may have different thermal events. Raw CGM and DDGS both showed an endothermic event at $86^{\circ} \mathrm{C}$ and was not melting of any crystalline regions (Figure 3 ). The endotherm at $86^{\circ} \mathrm{C}$ is probably due to amorphous chains tightly packing over time [26]. When heated, chain relaxation occurs, leading to an endothermic event. Adding urea and water had the same effect as heating and no endotherm was observed in the denatured raw materials due to the added chain mobility brought about the plasticizing effect of water in addition to the effect of urea.

Untreated and unprocessed proteins typically have a very high glass transition temperature, in the order of $200^{\circ} \mathrm{C}$. Literature suggests that CGM has a $T_{g}$ of $178^{\circ} \mathrm{C}$, which will overlap with water evaporation (endothermic peak) and is better detected using DMA. Urea is a strong protein denaturant, disrupting hydrogen bonding between protein chains. After denaturing (and plasticization) the $T_{g}$ of CGM dropped to $109^{\circ} \mathrm{C}$ and $60^{\circ} \mathrm{C}$ for DDGS (Table 2). Dry DDGS has been shown to have a $T_{g}$ in the region of $136^{\circ} \mathrm{C}$ and depends strongly on water content [27]. Although it appears that DDGS has a second transition at about 120 , it is more likely part of water evaporation.

3.2. Extrusion. After denaturing and plasticization, the $T_{g}$ (or softening point) of the materials is low enough to allow for extrusion and consolidation. Power consumption curves for each blend generally followed similar trends, with distinct changes after each chamber became completely filled (Figure 4). After the third chamber filled completely, peak power was reached after which the power consumption decreased as the first barrel started emptying again. All blends showed power consumption increasing over time due to frictional heating. Providing enough heat could lead to structural modification of the protein and, if plasticized, may lead to more power required for flow (as opposed to individual particles moving, for compressed powders). 

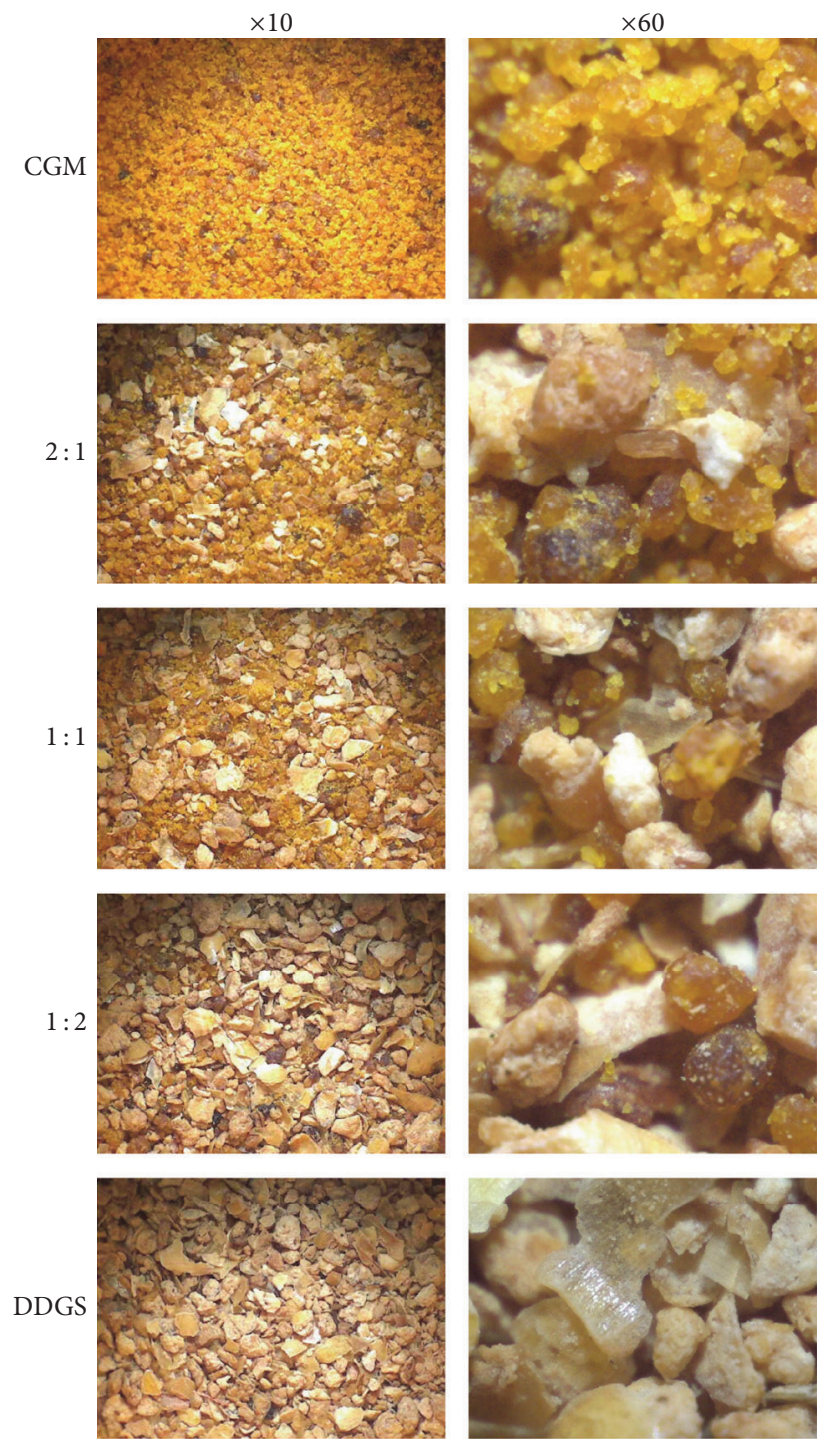

FIGURE 2: Optical images of CGM and DDGS particles at $\times 10$ and $\times 60$ magnification before denaturing or extrusion.

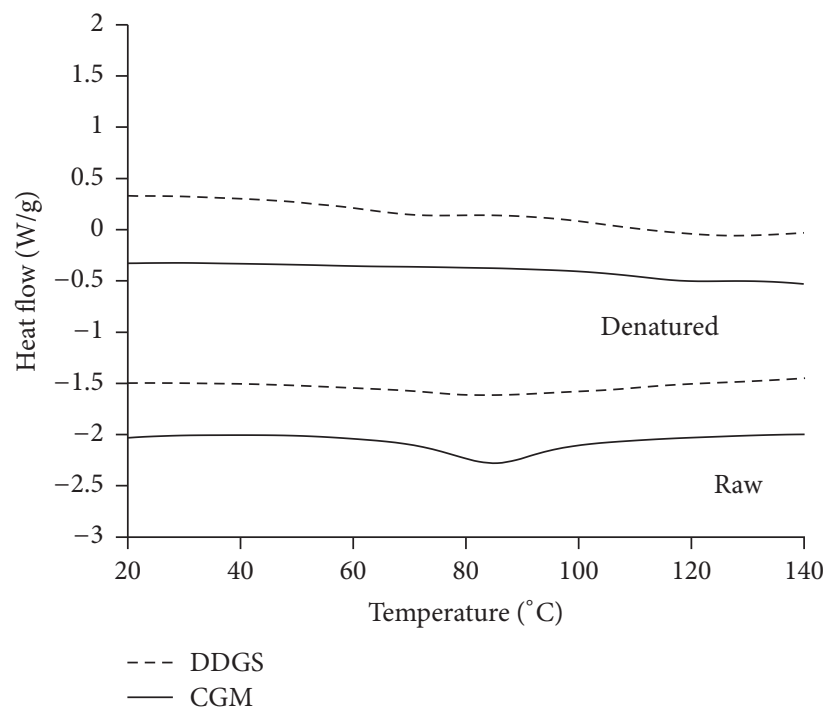

FIGURE 3: DSC thermograms of CGM and DDGS before and after denaturing. 


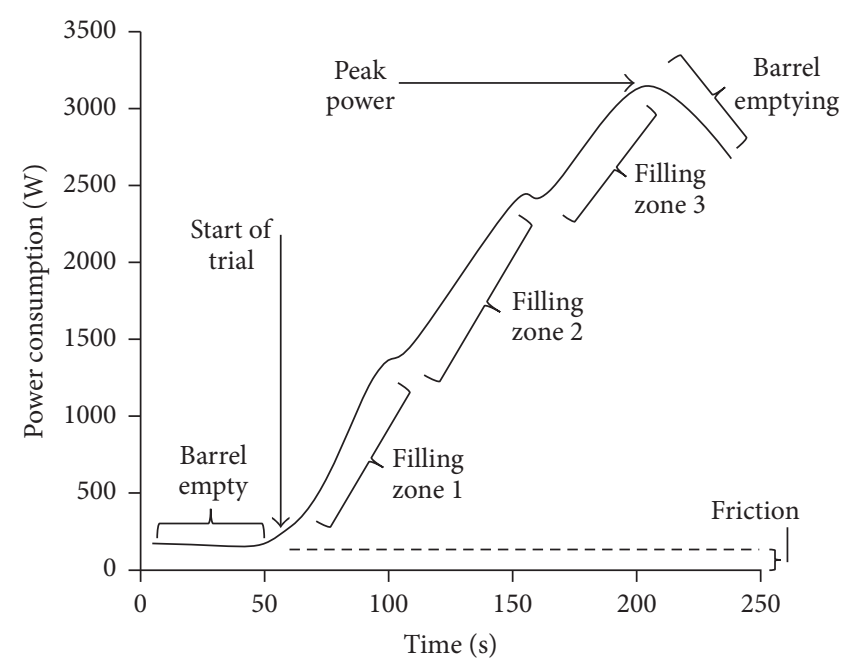

FIGURE 4: Generalized power consumption curve indicating different regions of power consumption during extrusion.

TABLE 2: Thermal events for CGM, DDGS, and blends thereof.

\begin{tabular}{lccc}
\hline Blend & $T_{\text {endo }}$ & $\begin{array}{c}T_{g, 1} \\
\left({ }^{\circ} \mathrm{C}\right)\end{array}$ & $T_{g, 2}$ \\
\hline CGM, raw & 86 & & \\
DDGS, raw & 86 & & \\
CGM, denatured & & 109 & \\
DDGS, denatured & & 60 & \\
CGM : DDGS $2: 1$, raw & 89 & & \\
CGM : DDGS $2: 1$, denatured & & 110 & \\
CGM : DDGS $2: 1$, extruded & & 60 & 108 \\
CGM : DDGS $1: 1$, raw & 89 & & \\
CGM : DDGS $1: 1$, denatured & & 110 & \\
CGM : DDGS $1: 1$, extruded & & 53 & 100 \\
CGM : DDGS $1: 2$, raw & 92 & & \\
CGM : DDGS $1: 2$, denatured & & 112 & \\
CGM : DDGS $1: 2$, extruded & & 56 & 102 \\
\hline
\end{tabular}

For CGM the rise in power consumption during the filling of each barrel section was much faster compared to DDGS. Although the time it took for each barrel to fill was not exactly the same, the time it took to reach maximum power was approximately the same (Figure 5). The higher protein fraction in CGM is probably the cause for the more rapid power increase as a viscoelastic melt is formed. However, if this melt is pseudoplastic (most thermoplastics are) a drop in power consumption will be observed. This behaviour was very evident in CGM and much less so for DDGS, as expected.

The difference between blends was much less pronounced with the rate of power increase being very similar in the first two zones. It should be noted that these curves have not been corrected for mass flow (i.e., SME) and the absolute value of power consumption is therefore insignificant in these figures.

What is evident from these curves, however, is that, at the end of each zone filling stage, there is a drop in power requirement and this was ascribed to the pseudoplastic nature of the formed melt. It was observed that DDGS had a relatively smaller drop in power consumption at the end of zones one and two. Furthermore, blends with increasing DDGS also showed less pseudoplasticity. This could be explained by the fact that DDGS contains significantly more cellulosic material, which cannot be plasticized as the protein fraction.

Integrating the power consumption data to determine the area under each power curve provided total energy consumed. Dividing total energy consumption (accounting for friction) by mass flow rate provided the specific mechanical energy consumption (SME). The greater the SME, the greater the power input per unit of product; some of this power was converted into frictional heating between the extruder screw and the material.

DDGS required more than twice the average power per kilogram of material than CGM $(715 \mathrm{~kJ} / \mathrm{kg}$ versus $335 \mathrm{~kJ} / \mathrm{kg})$ for extruding (Figure 6). This would indicate that DDGS did not form a semicontinuous pseudoplastic melt. This was also supported by morphology observations presented later. The peak power requirement per kilogram material showed a similar trend with increasing maximum power with increasing DDGS content. One would conclude that DDGS partially acts as a filler and disrupts the formation of a melt, if included in a too great proportion.

Temperature rise in the extruder barrel, both zone 1 (central extruder chamber) and zone 2 (chamber at which the material exited the die), increased over time (Figure 7). Zone 2 always had a much higher temperature response because that was the chamber where the majority of frictional energy was imparted to the dough; zone 1 was primarily a zone for material transfer (Figure 1). CGM appeared to heat more rapidly than did DDGS. As DDGS level in the blend increased, the maximum temperature in the extruder (both zone 1 and zone 2) had a curvilinear response, so that as DDGS level increased, processing temperatures, in general, declined.

The modest temperature increase associated with DDGS processing is indicative of its lack of melt formation, effectively requiring less dissipative heating. However, processing 

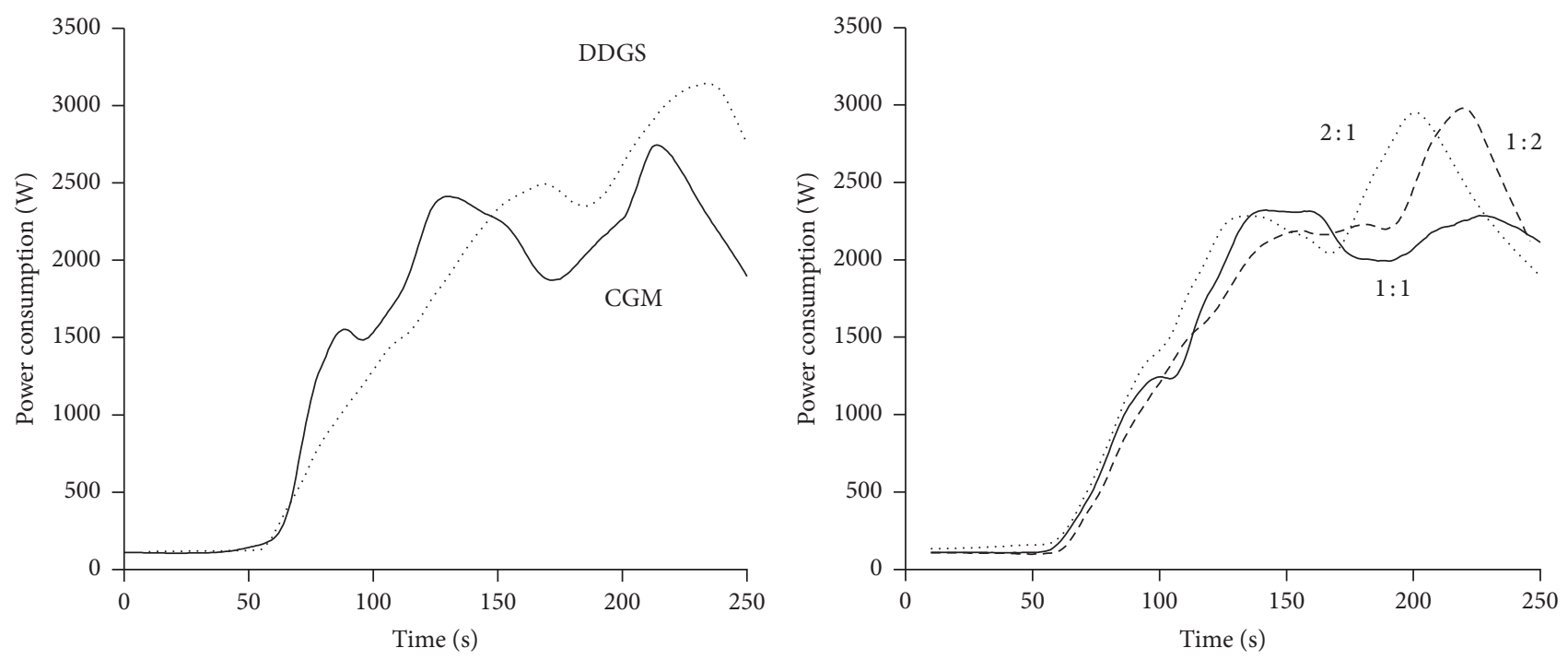

FIGURE 5: Power consumption during extrusion of CGM and DDGS blends.

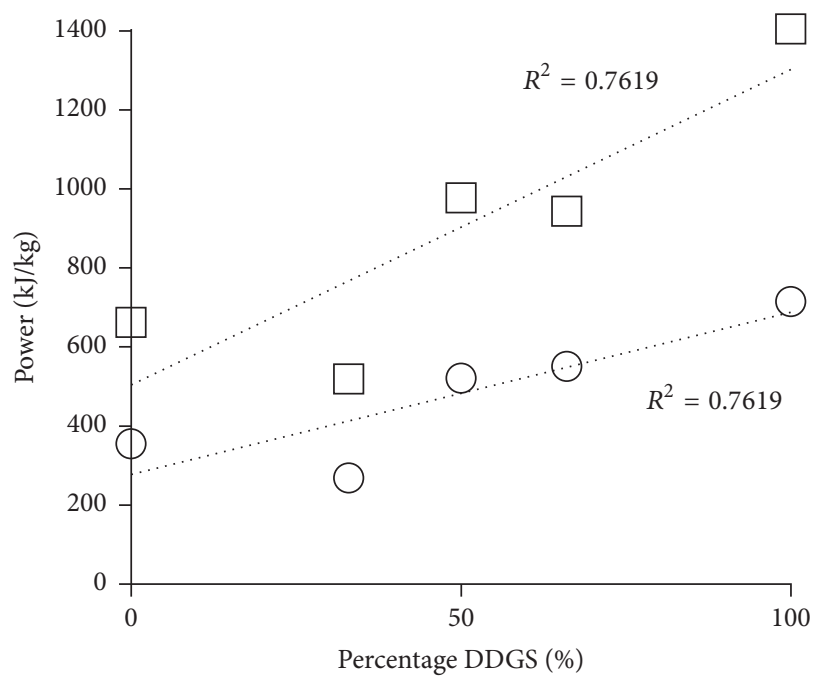

FIGURE 6: Power consumption during extrusion of CGM and DGS as a function of DDGS content. $\square$ : peak power; O: average power.

DDGS required more power, suggesting that, in the case of CGM where less power (lower viscosity) was required, a pseudoplastic melt had formed.

3.3. Consolidation. Figure 8 shows longitudinal and radial images of the extrudate as well as images from the material directly behind the die. Relatively poor consolidation was achieved even from pure CGM, which is slightly at odds with previous work. However, these materials were not injection moulded into test pieces but analysed directly after extrusion. Furthermore, the extruder setup precluded high pressure build up, typically required for consolidation. The cross-sectional images were used to quantify the degree of consolidation by using image analysis assuming black areas corresponded to consolidated material (Figure 9). Complete substitution of DDGS for CGM reduced the consolidation from about $60 \%$ to between 40 and $45 \%$. It was thought that the nonprotein fraction in DDGS would be the main reason for this reduction as the fibre content will not be able to be consolidated as part of the polymer matrix. Despite this, a semicontinuous extrudate still formed, suggesting enough consolidation required for bioplastic formation.

Pure DDGS consolidated poorly compared to CGM, although all the longitudinal images had a rather rough surface appearance getting progressively worse from $100 \%$ CGM to $100 \%$ DDGS. The poor surface appearance is likely due to the sudden pressure drop and high temperature at the extruder die, causing some degree of separation due to steam evaporation. Considering the images of the material behind the die, they appeared to be much better consolidated. However, adding DDGS to CGM did decrease the consolidated appearance of the material. 


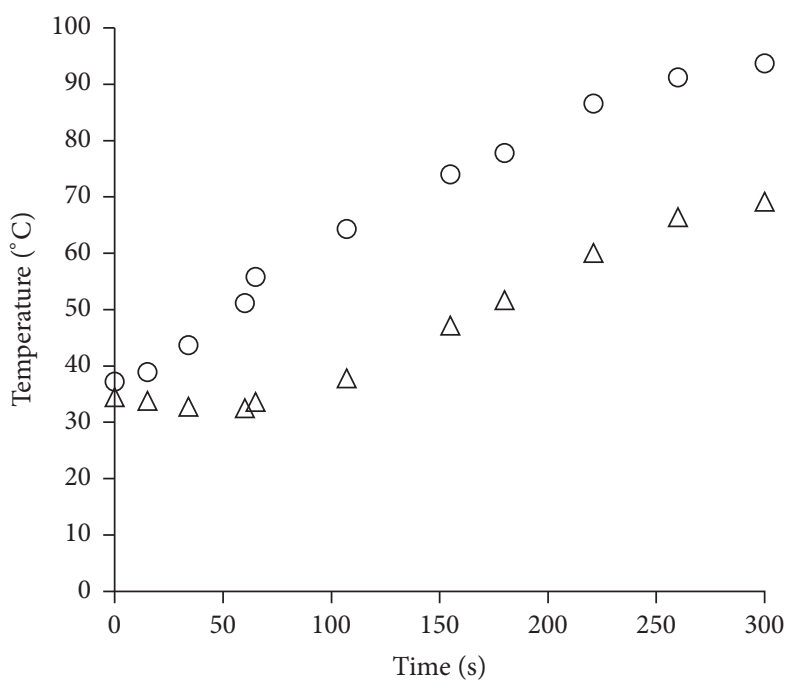

(a)

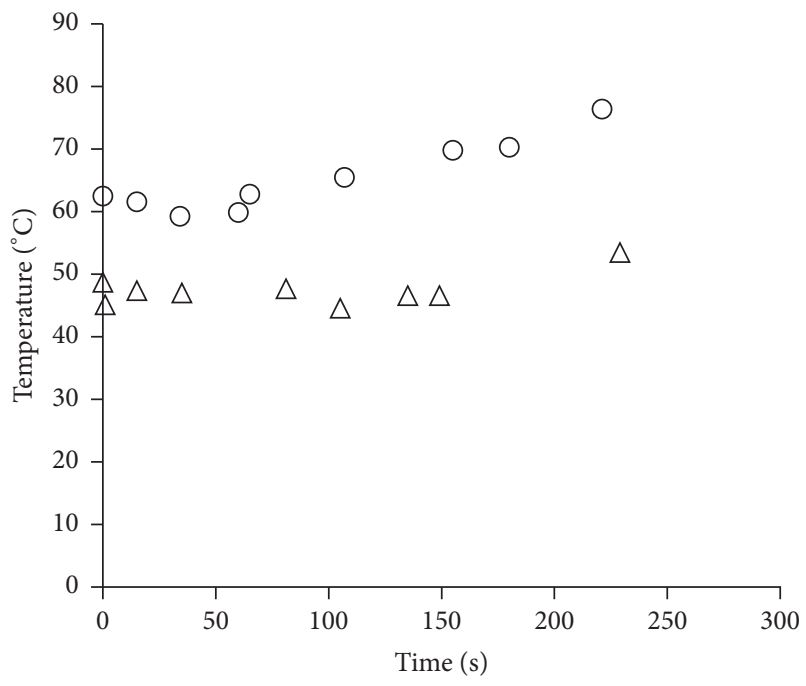

(b)

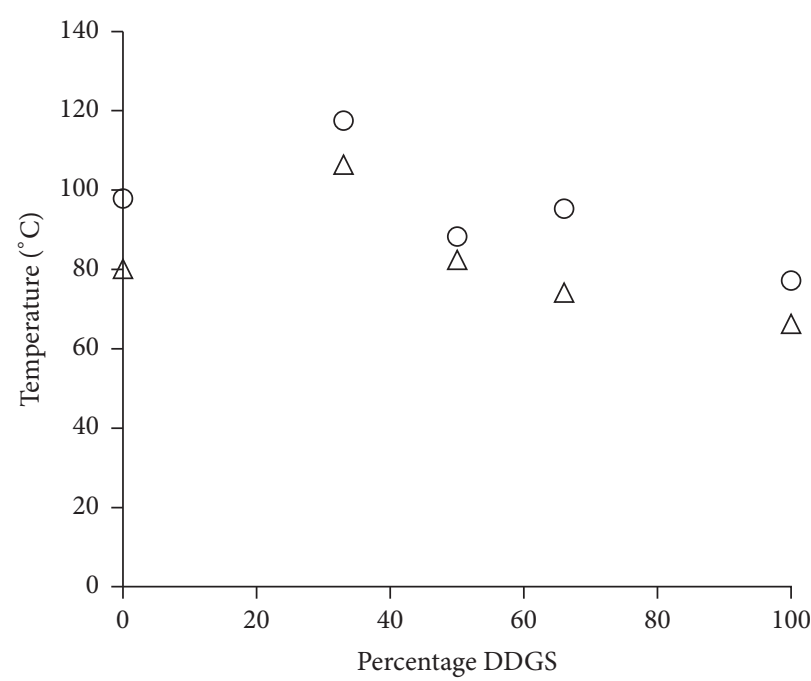

(c)

Figure 7: Temperature of zone $1\left(T_{1}\right)$ and zone $2\left(T_{2}\right)$ over time for extruding (a) CGM and (b) DDGS. (c) Maximum temperature during extrusion for blends. (O: zone $1 ; \triangle$ : zone 2$)$.

These results are consistent with the power consumption data, which indicated that extruding CGM or blends containing more CGM than DDGS required less power, because of the formation of a pseudoplastic melt. It would follow that this happens in parallel to consolidation.

It is important to remember that neither CGM nor DDGS are pure substances and are blends of proteins and carbohydrates (Table 1). The morphology of CGM and DDGS after denaturing and extrusion are still heterogeneous at a microscale. For TEM analysis, samples were stained with osmium tetroxide which preferentially stains carbohydrates over proteins (Figure 10). CGM appears to have more threadlike features compared to DDGS. DDGS had comparably darker regions that would be consistent to its higher carbohydrate content. For both materials, circular (or spherical) regions were present, surrounded with a thin layer of what appears to be protein.
In the $1: 1$ blend, the morphology appears to be much more homogenous, with a distinct absence of the spherical inclusions. It would appear that extrusion has led to some degree of dispersion of the various polymeric phases. The blend is clearly still phase separated on a microscale, but no evidence of poor interfacial adhesion was found. With TEM it was difficult to assess consolidation as the magnification was too high.

3.4. Thermal Properties. Blending polymers typically leads to specific thermal properties; an immiscible blend will show a glass transition temperature akin to each phase while a miscible blend will only have one $T_{g}$ (assuming both phases are amorphous) proportional to the composition of the blend. For a partially miscible system or a compatible blend, more than one $T_{g}$ is still observed, but the two $T_{g}$ s move closer together as compatibility is increased. 

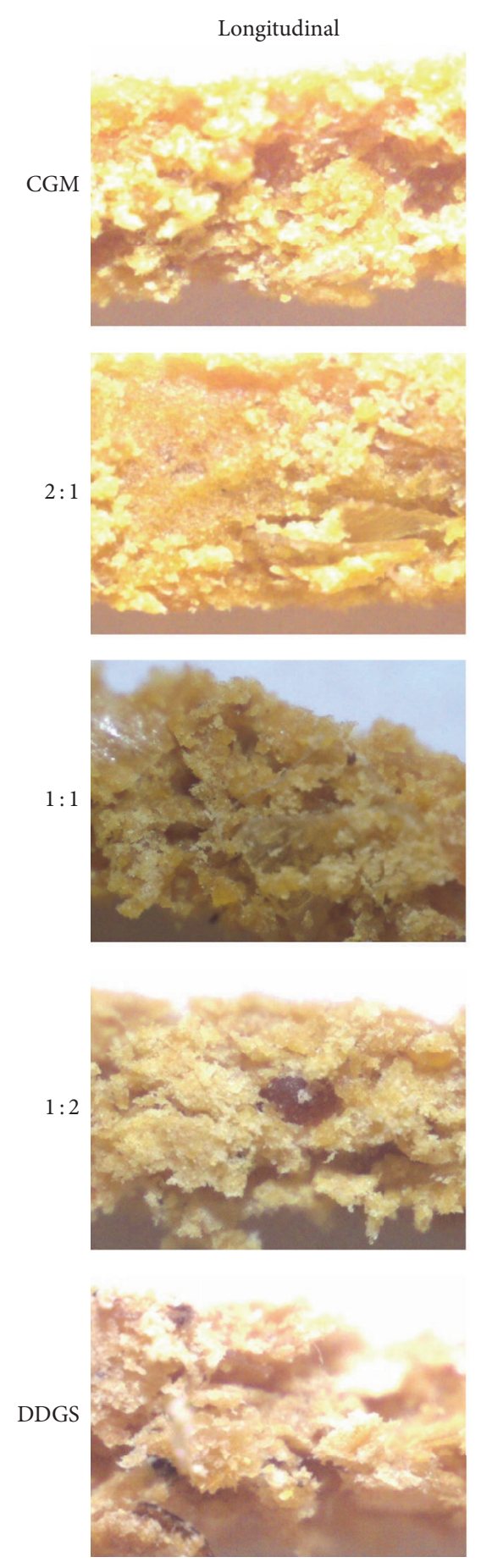

FIGURE 8: Optical images at $\times 60$ magnification of CGM and DDGS and their blends in the ratios shown.
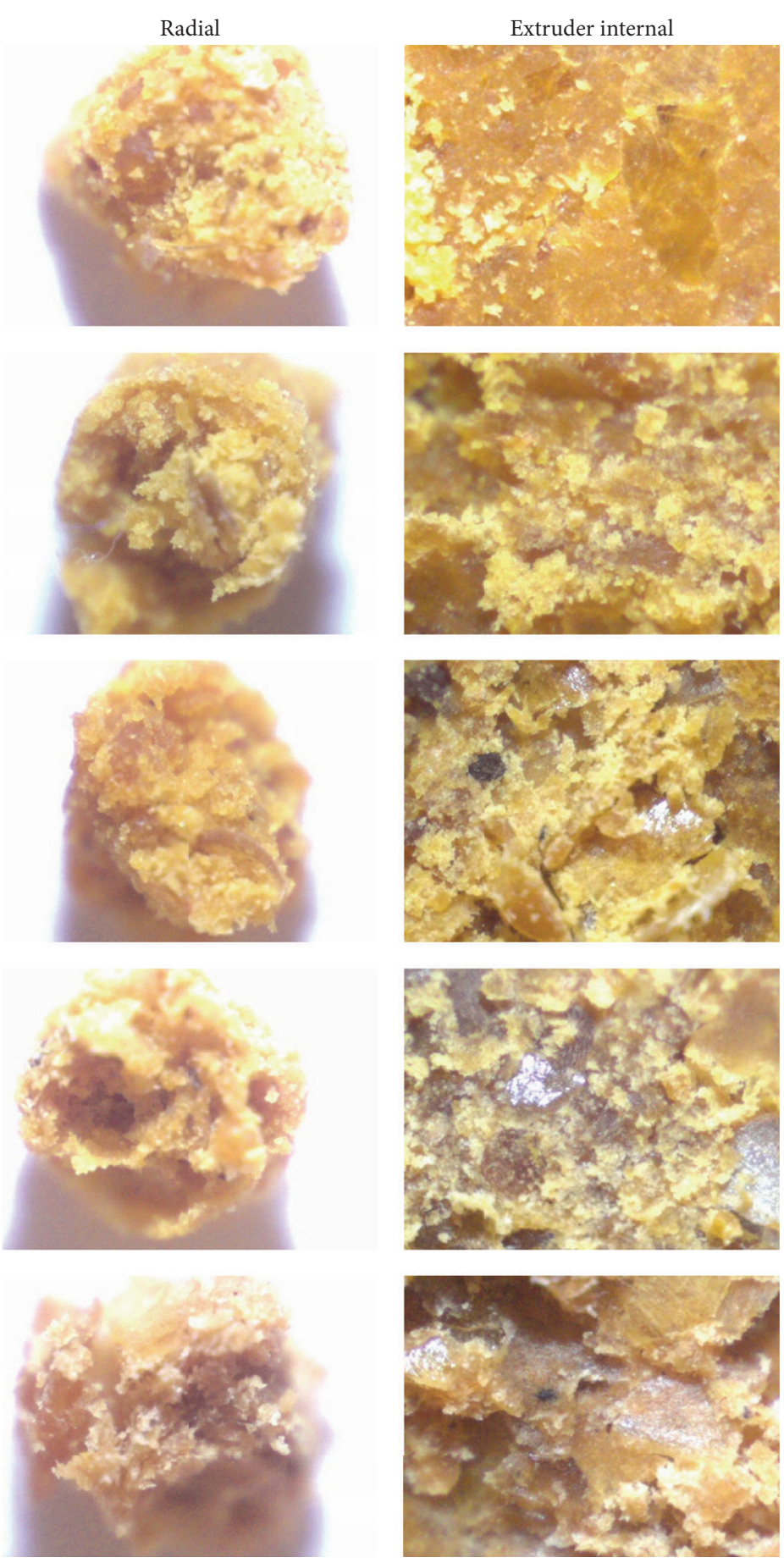

The thermal properties of CGM and DDGS are complex as both these materials are in fact blends of different protein fractions as well as carbohydrates; each of these could give rise to a distinct $T_{g}$ (Figure 11). CGM and DDGS both showed thermal transitions thought to be associated with thermal transitions of different materials in each feed protein. For CGM/DDGS blends before any modification, the same endotherm at approximately $86^{\circ} \mathrm{C}$ was observed. Because of water evaporation (endotherm obscuring other events) no glass transition was observed. That is not to say that there were none, but it is likely that the $T_{g}$ s for CGM and DDGS are both closer to $200^{\circ} \mathrm{C}$. After adding water and urea as a denaturant, the endothermic peak, thought to be an aging peak, disappears because of the increased chain mobility. For the same reason, a glass transition at around $110^{\circ} \mathrm{C}$ is observed for all the denatured blends before extrusion. 


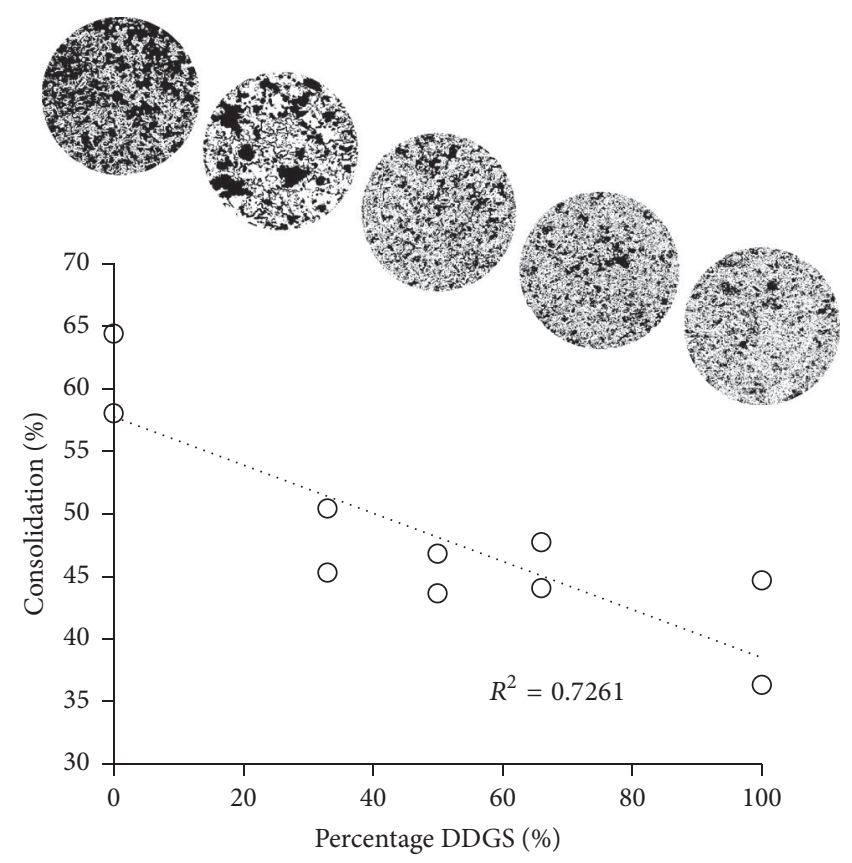

FIgURE 9: Percentage consolidation as a function of DDGS content.

TABLE 3: Moisture content of CGM and DDGS before and after extrusion, based on adding water and urea in the amounts shown per $100 \mathrm{~g}$ CGM or DDGS.

\begin{tabular}{lcc}
\hline & CGM & DDGS \\
\hline${\text { Dry matter }(\mathrm{g})^{*}}_{\text {Initial water }(\mathrm{g})^{*}}$ & 90.8 & 98 \\
Added water $(\mathrm{g})^{*}$ & 9.2 & 2 \\
Urea $(\mathrm{g})^{*}$ & 50 & 50 \\
Moisture (\%) & 10 & 10 \\
$\quad$ Before extrusion & & \\
$\quad$ After extrusion & 37 & 32.5 \\
\hline
\end{tabular}

${ }^{*}$ Per 100 g CGM or DDGS.

Extrusion led to further changes in the thermal behaviour of the blends. In all cases, two $T_{g} s$ were observed: one at $\sim 60$ and one at $\sim 100^{\circ} \mathrm{C}$. Extrusion will lead to disruption of existing chain interactions and to the formation of new interactions. Both these processes will lead to changes in thermal behaviour of the blend. For the CGM/DDGS blends it would appear that the observed $T_{g}$ s represent the $T_{g} s$ of CGM and DDGS, respectively, suggesting that these form an incompatible blend. Based on the morphology, one would conclude that the blends are certainly not miscible on a molecular scale, but interfacial adhesion is probably adequate for the blend to behave as a compatible blend. Based on these results, it is likely that the properties of these blends could be further improved with the incorporation of other additives that would promote miscibility.
Another factor not considered explicitly here is moisture content. It is well known that water is a plasticizer for both proteins and carbohydrates. The apparent indifference between the $T_{g}$ values of the blends could be due to water (Table 3 ). Increasing water content will reduce the $T_{g}$ significantly and for the current work, extruding CGM led to a slightly higher moisture loss compared to DDGS. Blends with more CGM could therefore have a slightly higher $T_{g}$, than if all the blends had the same moisture content.

\section{Conclusions}

Corn-based protein sources consist of a blend of carbohydrates and protein. CGM has a higher proportion protein and is easier to consolidate into a monolithic material compared to DDGS, which contains almost twice as much cellulose as CGM, while CGM is rich in protein, a requirement for successful thermoplastic processing. This study has shown that thermoplastics based on CGM can be made cheaper by filling with DDGS. Since both these materials are corn-based, a semicompatible blend is formed but using a majority of DDGS led to higher power requirements for processing and was detrimental to consolidation.

\section{Competing Interests}

The authors declare that they have no competing interests.

\section{Acknowledgments}

The authors would like to thank the following people for the invaluable contribution to completing the experimental 


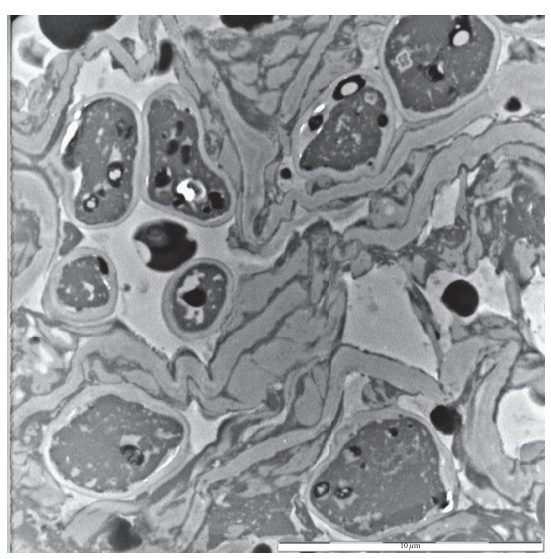

(a)

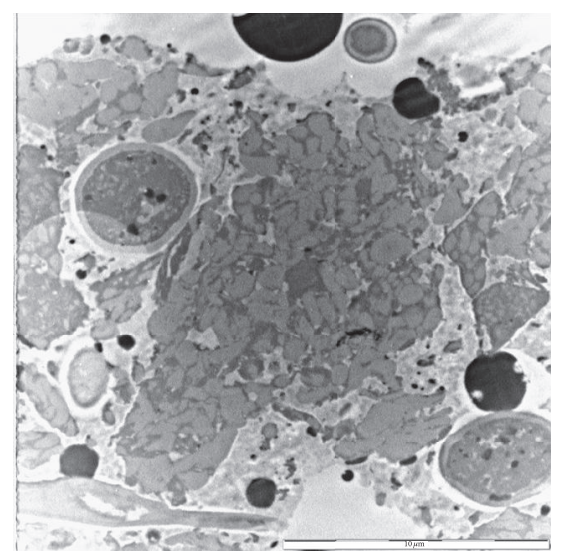

(b)

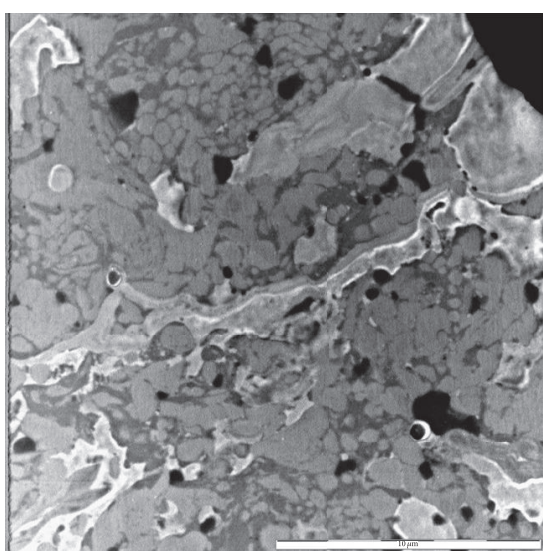

(c)

FIGURE 10: TEM Images of (a) CGM, (b) DDGS, and (c) CGM: DDGS 1:1. Scale bar represents $10 \mu \mathrm{m}$.

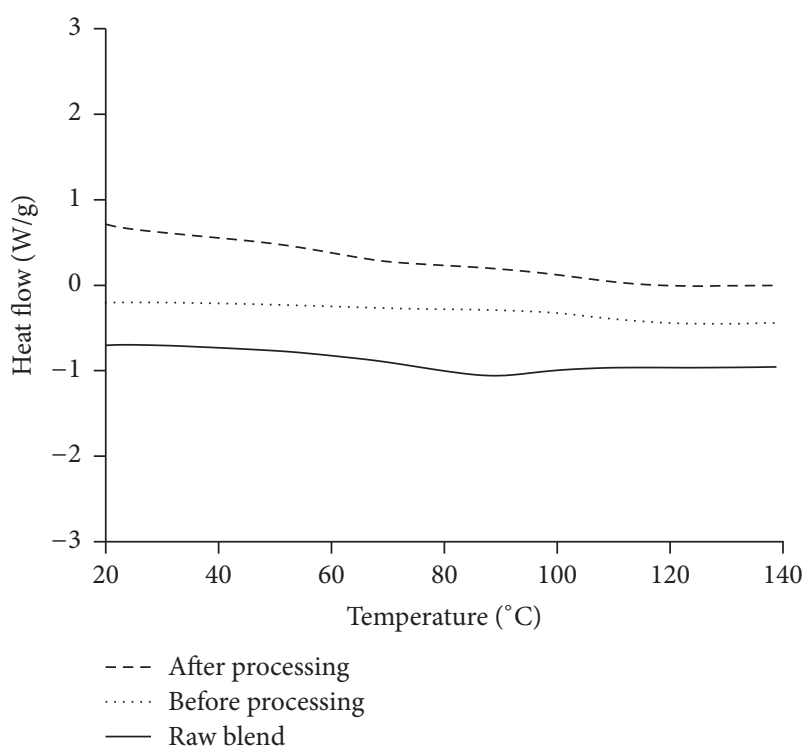

(a)

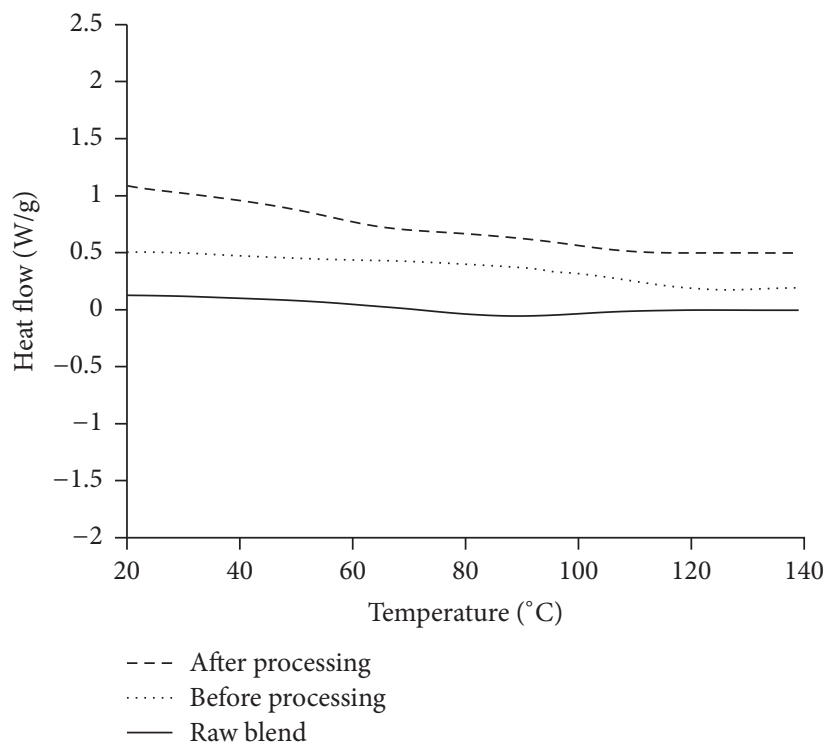

(b)

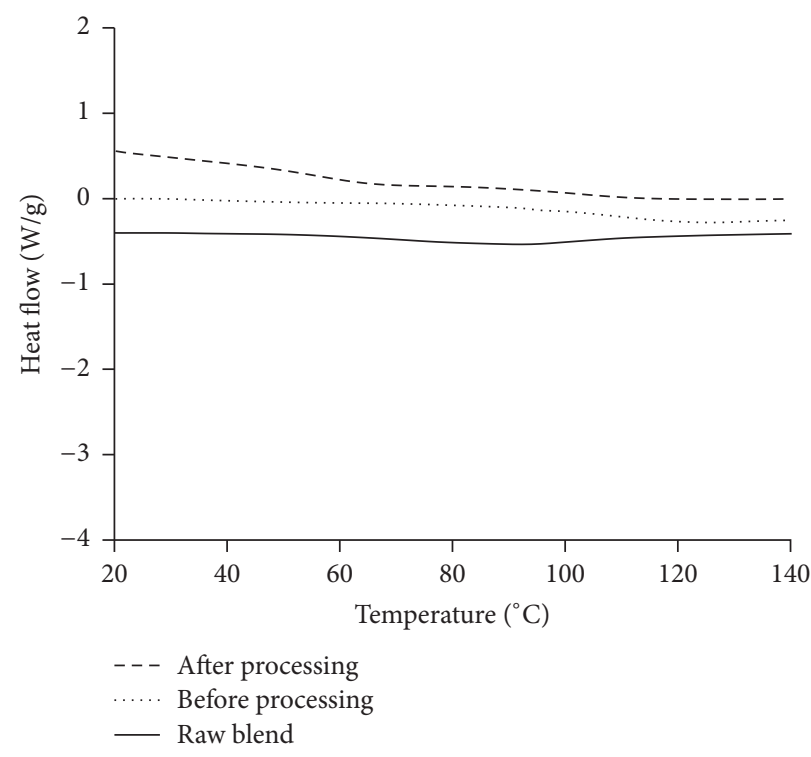

(c)

FIGURE 11: DSC Thermograms of blends between CGM and DDGS. (a) $-2: 1 ;$ (b) $-1: 1 ;$ (c) $-1: 2$. 
work: Sharon Nichols, Christine Wood, Kamal Mjoun, and Tony Nielson. Also the authors wish to acknowledge help of Chris van der Merwe from the Laboratory for Microscopy and Microanalysis, University of Pretoria, for his technical assistance on the TEM.

\section{References}

[1] A. Gandini, "Polymers from renewable resources: a challenge for the future of macromolecular materials," Macromolecules, vol. 41, no. 24, pp. 9491-9504, 2008.

[2] F. Chivrac, E. Pollet, and L. Avérous, "Progress in nano-biocomposites based on polysaccharides and nanoclays," Materials Science and Engineering R: Reports, vol. 67, no. 1, pp. 1-17, 2009.

[3] C. J. R. Verbeek and J. M. Bier, "Synthesis and characterization of thermoplastic agro-polymers," in Handbook of Applied Biopolymer Technology, S. K. Sharma and A. Mudhoo, Eds., pp. 197-242, RSC Publishing, 2011.

[4] K. Liu and K. A. Rosentrater, Distillers Grains: Production, Properties, and Utilization, Taylor and Francis/CRC Press, Boca Raton, Fla, USA, 2011.

[5] L. A. Johnson and J. B. May, "Wet milling: the basis for corn biorefineries," in Corn: Chemistry and Technology, P. J. White and L. A. Johnson, Eds., pp. 449-495, American Association of Cereal Chemists, St. Paul, Minn, USA, 2003.

[6] D. D. Loy and K. N. Wright, "Nutritional properties and feeding value of corn and its by-products," in Corn: Chemistry and Technology, P. J. White and L. A. Johnson, Eds., pp. 571-604, American Association of Cereal Chemists, Saint Paul, Minn, USA, 2003.

[7] R. J. Bothast and M. A. Schlicher, "Biotechnological processes for conversion of corn into ethanol," Applied Microbiology and Biotechnology, vol. 67, no. 1, pp. 19-25, 2005.

[8] K. L. Pickering, C. J. R. Verbeek, and C. Viljoen, “The effect of aqueous urea on the processing, structure and properties of CGM," Journal of Polymers and the Environment, vol. 20, no. 2, pp. 335-343, 2012.

[9] L. A. De Graaf, "Denaturation of proteins from a non-food perspective," Journal of Biotechnology, vol. 79, no. 3, pp. 299306, 2000.

[10] J. K. Sears and J. R. Darby, "Mechanism of plasticiser action," in The Technology of Plasticizers, J. K. Sears and J. R. Darby, Eds., pp. 33-77, John Wiley \& Sons, New York, NY, USA, 1982.

[11] J. S. Richardson, "The anatomy and taxonomy of protein structure," Advances in Protein Chemistry, vol. 34, pp. 167-339, 1981.

[12] D. Whitford, Proteins Structure and Function, John Wiley and Sons, Chichester, UK, 2005.

[13] C. J. R. Verbeek and L. E. Van Den Berg, "Extrusion processing and properties of protein-based thermoplastics," Macromolecular Materials and Engineering, vol. 295, no. 1, pp. 10-21, 2010.

[14] H. C. Huang, T. C. Chang, and J. Jane, "Mechanical and physical properties of protein-starch based plastics produced by extrusion and injection molding," Journal of the American Oil Chemists' Society, vol. 76, no. 9, pp. 1101-1108, 1999.

[15] L. di Gioia, B. Cuq, and S. Guilbert, "Effect of hydrophilic plasticizers on thermomechanical properties of corn gluten meal," Cereal Chemistry, vol. 75, no. 4, pp. 514-519, 1998.

[16] L. Di Gioia, B. Cuq, and S. Guilbert, "Plasticization of corn gluten meal and characterization of the blends," Macromolecular Symposia, vol. 144, no. 1, pp. 365-369, 1999.
[17] L. Di Gioia and S. Guilbert, "Corn protein-based thermoplastic resins: effect of some polar and amphiphilic plasticizers," Journal of Agricultural and Food Chemistry, vol. 47, no. 3, pp. 12541261, 1999.

[18] L. A. Danzer, H. Ades, and E. D. Rees, "The helical content of zein, a water insoluble protein, in non-aqueous solvents," Biochimica et Biophysica Acta (BBA)_Protein Structure, vol. 386, no. 1, pp. 26-31, 1975.

[19] A. Esen, "A proposed nomenclature for the alcohol-soluble proteins (zeins) of maize (Zea mays L.)," Journal of Cereal Science, vol. 5, no. 2, pp. 117-128, 1987.

[20] H. C. Nielsen, J. W. Paulis, C. James, and J. S. Wall, "Extraction and structure studies on corn glutelin proteins," Cereal Chemistry Journal, vol. 47, no. 5, pp. 501-512, 1970.

[21] J. S. Wall, L. A. Cooker, and J. A. Bietz, "Structure and origin of maize endosperm alcohol-insoluble glutelin," Journal of Agricultural and Food Chemistry, vol. 36, no. 4, pp. 722-728, 1988.

[22] S. Sánchez Del Angel, E. Moreno Martínez, and M. A. Valdivia López, "Study of denaturation of corn proteins during storage using differential scanning calorimetry," Food Chemistry, vol. 83, no. 4, pp. 531-540, 2003.

[23] K. A. Rosentrater and C. J. R. Verbeek, "Processibility of corn protein blends and resulting properties of the extrudates," in Proceedings of the Quality of Life Through Chemical Engineering (Chemeca '12), pp. 1127-1136, Wellington, New Zealand, September 2012.

[24] J. A. Saunders and K. A. Rosentrater, "Properties of solvent extracted low-oil corn distillers dried grains with solubles," Biomass and Bioenergy, vol. 33, no. 10, pp. 1486-1490, 2009.

[25] K. Mjoun and K. A. Rosentrater, "Extruded aquafeeds containing distillers dried grains with solubles: effects on extrudate properties and processing behaviour," Journal of the Science of Food and Agriculture, vol. 91, no. 15, pp. 2865-2874, 2011.

[26] J. M. Bier, C. J. R. Verbeek, and M. C. Lay, "Thermal transitions and structural relaxations in protein-based thermoplastics," Macromolecular Materials and Engineering, vol. 299, no. 5, pp. 524-539, 2014.

[27] A. R. P. Kingsly and K. E. Ileleji, "Glass transition behavior of corn distillers dried grains with solubles (DDGS)," Journal of Cereal Science, vol. 54, no. 3, pp. 332-338, 2011. 

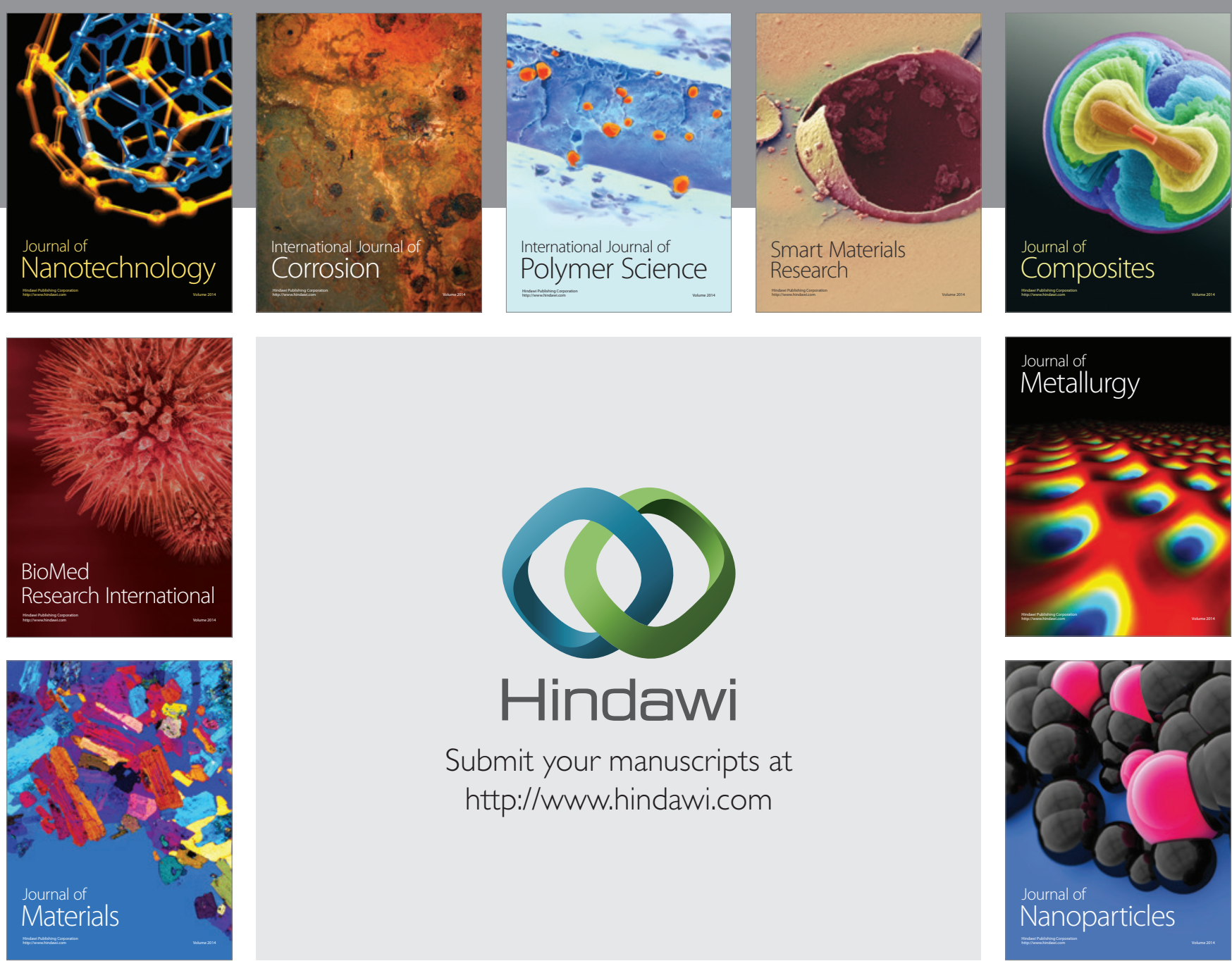

\section{Hindawi}

Submit your manuscripts at

http://www.hindawi.com

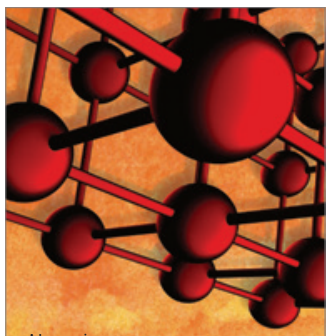

Materials Science and Engineering
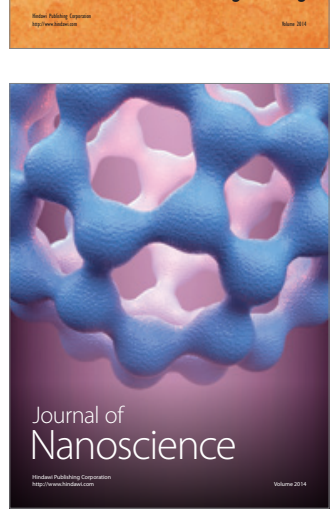
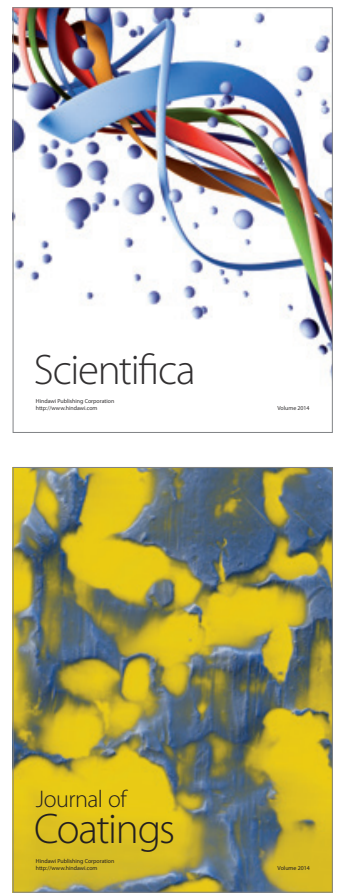
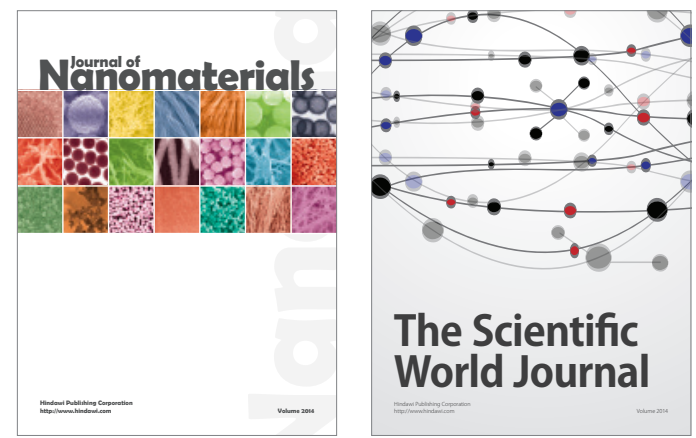

The Scientific World Journal
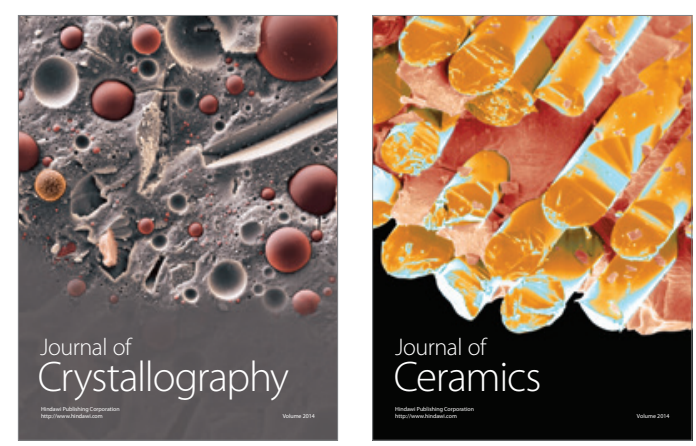
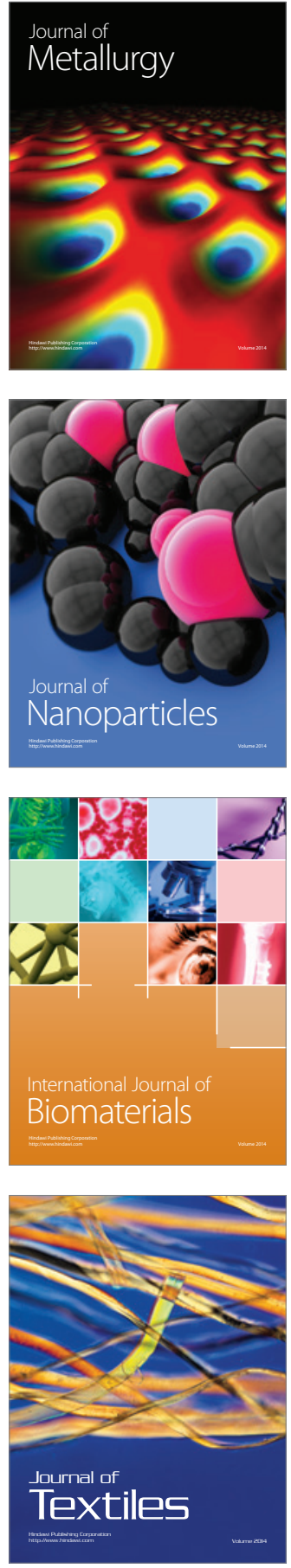